\title{
Refractory Malignant Neoplasm of Multiple Primary Sites
}

National Cancer Institute

\section{Source}

National Cancer Institute. Refractory Malignant Neoplasm of Multiple Primary Sites. NCI

Thesaurus. Code C150529.

Malignant neoplasm of multiple primary sites that is resistant to treatment. 